\title{
Currículo de Ciências: estabilidade e mudança em livros didáticos ${ }^{\prime}$
}

Maria Margarida Gomes"

Sandra Escovedo Selles'll

Alice Casimiro Lopes ${ }^{\mathrm{IV}}$

\section{Resumo}

0 estudo focaliza aspectos relacionados aos conteúdos de ensino presentes em livros didáticos de Ciências no período entre as décadas de 1970 e 2000. A partir de questões que buscam compreender como vem se dando sócio-historicamente a valorização dos conhecimentos ecológicos nos currículos dessa disciplina, a análise prioriza as relações estabelecidas entre tais conhecimentos e outras temáticas também ensinadas. Para tanto, os conteúdos de ecologia selecionados para ensino são considerados resultantes de aspectos relativos à produção científica da ecologia biológica, ao ensino de Ciências, ao campo educacional e aos movimentos ambientais. Assim, com a finalidade de compreender a inserção de conhecimentos ecológicos nos currículos brasileiros de Ciências, identificam-se enfoques curriculares articulados às seleções de conteúdos de ensino e investigam-se as relações estabelecidas entre esses conhecimentos e outras temáticas dessa disciplina escolar em livros didáticos destinados ao ensino fundamental. Com base principalmente nas discussões de Ivor Goodson, evidencia-se a trajetória sócio-histórica dos currículos de Ciências por uma relação interdependente entre padrões de estabilidade e de mudança. Argumenta-se que os conteúdos de ecologia são introduzidos, causando mudança, na medida em que se inserem num padrão de estabilidade. Nessa perspectiva, tais materiais são tratados como fontes históricas importantes para entender a produção curricular escolar desenvolvida no período em questão.

\section{Palavras-chave}

I- Esta é uma versão ampliada do trabalho apresentado no VII ENPEC - Encontro Nacional de Pesquisa em Educação em Ciências, realizado em 2009.

II- Universidade Federal do Rio de Janeiro, Rio de Janeiro, RJ, Brasil.

Contato: margaridaplgomes@gmail.com

III- Universidade Federal Fluminense, Niterói, RJ, Brasil.

Contato: escovedoselles@gmail.com

IV- Universidade do Estado do Rio de Janeiro, Rio de Janeiro, RJ, Brasil.

Contato: alice@curriculo-uerj.pro.br 


\title{
Science curriculum: stability and change in textbooks
}

\author{
Maria Margarida Gomes" \\ Sandra Escovedo Selles'll \\ Alice Casimiro Lopes ${ }^{\text {IV }}$
}

\begin{abstract}
This study focuses on aspects related to the contents present in Science textbooks during the period between the 1970s and 2000s. Based on questions that seek to understand how the valuation of ecological knowledge has taken place socio-historically in the curricula of this discipline, the analysis gives priority to the relations established between such knowledge and other themes also taught. For that, the ecology contents selected for teaching are considered as resulting from aspects related to the scientific production in biological ecology, to the teaching of Sciences, to the educational field and to environmental movements. Thus, with the intent of understanding the inclusion of ecological knowledge in Brazilian curricula in Sciences, we identify curriculum approaches articulated with the selection of teaching contents, and we investigate the relations established between this knowledge and other themes from this school discipline in textbooks targeted at primary education. Drawing mainly from discussions by Ivor Goodson, we detail the socio-historical trajectory of Sciences curricula through an interdependent relationship between patterns of stability and of change. We argue that ecology contents are introduced, causing change, whilst inserting themselves in a pattern of stability. Under such perspective, materials are treated as important historic sources to understand the school curriculum production developed in the period under study.
\end{abstract}

\section{Keywords}

Sciences curriculum - History of school disciplines - Curriculum

I- This text is an expanded version of the work approaches - Curriculum and stability - Curriculum change. presented to the Th ENPEC - Encontro Nacional de Pesquisa em Educação em Ciências (National Meeting in Research in Science Education) conducted in 2009.

II- Universidade Federal do Rio de Janeiro, Rio de Janeiro, RJ, Brazil.

Contact:margaridaplgomes@gmail.com

III- Universidade Federal Fluminense, Niterói, RJ, Brazil.

Contact: escovedoselles@gmail.com

IV- Universidade do Estado do Rio de Janeiro, Rio de Janeiro, RJ, Brazil.

Contact: alice@curriculo-uerj.pro.br 
0 estudo focaliza as relações estabelecidas entre os conhecimentos ecológicos e outras temáticas também ensinadas na disciplina escolar Ciências a partir de questões que buscam compreender como vem ocorrendo, sócio-historicamente, a valorização desses conhecimentos nos currículos dessa disciplina. Para tanto, a análise considera os conteúdos de ecologia selecionados para ensino como resultantes de aspectos relativos à produção científica da ecologia biológica, ao ensino de Ciências, ao campo educacional e aos movimentos ambientais.

Com esses objetivos, o trabalho analisa aspectos sócio-históricos relacionados aos conteúdos de ensino em livros didáticos de Ciências. Reconhecendo que sua apropriação é extremamente diversa nos múltiplos contextos das práticas curriculares, como as salas de aula, os livros didáticos são considerados guias curriculares que expressam influências de movimentos educacionais, científicos e cotidianos. Nessa perspectiva, tais materiais são tratados como fontes históricas importantes para entender a produção curricular escolar desenvolvida em dado período.

Compreendendo os livros didáticos como expressão das produções de conhecimento da disciplina escolar Ciências, o trabalho apoia-se nos estudos históricos de Ivor Goodson (1983, 1996, 1997, 1998, 2001) sobre as disciplinas escolares, particularmente seus conceitos de estabilidade e mudança. As relações entre esses dois conceitos são exploradas a partir da ecologia e de outras temáticas consideradas relevantes na disciplina Ciências. Consideram-se ainda, em diálogo com Goodson, os trabalhos de André Chervel (1990) e Dominique Julia (2001, 2002).

Os livros didáticos selecionados são produções brasileiras do período compreendido entre as décadas de 1970 e 2000; a partir de sua análise, apresentam-se evidências de padrões de estabilidade e mudança na trajetória sócio-histórica da disciplina. Enfoques curriculares do ensino de Ciências são analisados articulando-se às seleções de conteúdos de ensino referenciados na ecologia. A produção curricular desses materiais é examinada em face dos contextos sócio-históricos em que o ensino de Ciências vem se constituindo.

Considera-se que os livros investigados expressam finalidades, conteúdos e métodos relacionados a visões de ensino de Ciências e de formação geral dos jovens dos momentos históricos em que esses materiais são produzidos. Desse modo, eles formam um conjunto de conhecimentos referenciados em diversos campos científicos, mas sempre mediados por práticas e valores escolares. A análise dos livros didáticos selecionados possibilita a compreensão de aspectos que compõem a história dos conhecimentos ecológicos na disciplina Ciências. Além disso, visa contribuir para o entendimento dos conteúdos de caráter ecológico presentes nesses materiais como produtos sociais das variadas maneiras de compreendê-los na história do ensino.

0 trabalho está organizado em três seções. $\mathrm{Na}$ primeira, são apresentadas as concepções teóricas acerca das disciplinas escolares que servem de base para a análise dos livros didáticos. Na segunda, esses materiais são discutidos como fontes de estudos sócio-históricos. Já na terceira seção, a análise dos livros didáticos é apresentada, seguida pelas considerações fınais.

\section{Transformações sócio-históricas das disciplinas escolares}

Os currículos são, em geral, constituídos e organizados disciplinarmente em diferentes espaços e tempos. Essa prevalência do currículo disciplinar levou Kliebard (apud GOODSON, 1997) a se referir às disciplinas como a fortaleza inexpugnável do ensino secundário norte-americano. Múltiplas influências - incluindo embates e disputas decisivas na definição de quais conteúdos, métodos e objetivos são legítimos contribuem historicamente para a constituição das disciplinas escolares e têm sido objeto de estudo de autores como Ivor Goodson (1983, 1996, 1997, 1998, 2001), André Chervel (1990) e Dominique Julia (2001, 2002).

Os trabalhos de Chervel (1990) e Julia (2001, 2002) ressaltam a importância das 
finalidades educacionais que, sendo alteradas ao longo da história, promovem mudanças nas estruturas disciplinares. Segundo Chervel (1990), as disciplinas escolares são representações culturais criadas e consolidadas pelos processos de escolarização a partir de finalidades estabelecidas para a educação das gerações mais jovens. Dessa forma, elas são expressões dessas finalidades, dos conteúdos ensinados e dos resultados concretos dos processos de ensino, apresentando autonomia em relação às ciências de referência. Entretanto, ao longo de períodos históricos, as disciplinas escolares resultam de processos de manutenção e de mudança, uma vez que estão intrinsecamente ligadas às finalidades da educação escolar. As mudanças em tais finalidades acabam por suscitar, junto com as demandas do público escolar, transformações nas disciplinas.

Para Chervel (1990), as instituições escolares têm a função social de instruir os jovens, mas também de criar disciplinas cuja linguagem específica se traduz numa autonomia que as transforma em objetos culturais da sociedade. Portanto, o foco de seus estudos se volta à cultura escolar, mais especificamente à natureza intrínseca das disciplinas escolares. Julia (2001) compartilha dessa perspectiva considerando a cultura escolar como conjuntos de normas e práticas que definem conhecimentos e condutas a ensinar e a transmitir às gerações mais jovens com base em finalidades educacionais, sociais, religiosas, sociopolíticas ou simplesmente de socialização, que variam historicamente.

Dirigindo o foco para as teorias curriculares, campo de nosso interesse, Goodson (1983) sustenta que as disciplinas escolares não podem ser caracterizadas como entidades naturais e imutáveis, mas como amálgamas com características de grupos e tradições sociais, formando-se a partir de finalidades vinculadas a tradições utilitárias (ligadas aos interesses cotidianos das pessoas), pedagógicas (associadas à aprendizagem dos estudantes) e acadêmicas (voltadas para os interesses da formação universitária). As disciplinas passam por mudanças históricas e os debates acerca delas podem ser analisados em termos de conflitos por status, recursos e territórios (GOODSON, 1983).

Baseado em análises sócio-históricas de disciplinas específicas, Goodson (1983) utiliza-se do modelo de Layton (1973) para concluir que as finalidades utilitárias e pedagógicas predominam no processo de emergência de uma disciplina escolar. No entanto, o autor afirma que a consolidação de tais finalidades tende a se desenvolver na medida em que elas se aproximam das ciências de referência e das universidades. A linearidade histórica desse modelo torna-o limitado para interpretações que atentem para a variedade de espaços sociais e institucionais em que as disciplinas escolares tomam forma. Considerando tal limitação, a ideia de oscilação temporal entre as tradições utilitárias, pedagógicas e acadêmicas proposta por Lopes (2000) e Selles e Ferreira (2005) parece ser uma forma mais abrangente de explicar as transformações históricas pelas quais passam as disciplinas. Lopes (2000), ao analisar o currículo de Ciências no Colégio de Aplicação da Universidade Federal do Rio de Janeiro (UFRJ) entre 1969 e 1998, aponta uma trajetória que mescla, de forma não linear, as tradições utilitárias, pedagógicas e acadêmicas. Da mesma forma, Selles e Ferreira (2005) sugerem que os conteúdos de ensino da disciplina escolar Biologia relacionados ao tema da reprodução humana, apesar de fortemente vinculados a finalidades de natureza acadêmica, vêm sendo também selecionados a partir de finalidades de caráter utilitário e pedagógico.

Goodson (1997) defende haver fortes mecanismos sociais operando simultaneamente em duas dimensões curriculares que se interpenetram, o que resulta em padrões de estabilidade e de mudança. Nesse sentido, o autor se apropria das categorias institucionais de Meyer (apud GOODSON, 1997) para defender que os componentes organizacionais (internos à vida escolar, como as ações de professores e alunos) e os institucionais (externos à escola, como níveis de ensino e tópicos curriculares) são o 
palco de conflitos entre os atores sociais, fruto das diferenças entre esses níveis de organização dos sistemas escolares. Em sua interpretação, existe uma tendência à manutenção de determinados padrões disciplinares. Mesmo com a existência de contínuas divergências históricas entre os grupos e subgrupos que influenciam e dominam as decisões curriculares, a manutenção de padrões disciplinares é comum, sustentando as disciplinas e sendo sustentada por elas na estruturação dos currículos. Isso não significa, contudo, que as possibilidades de mudança sejam inexistentes. Ao contrário, as transformações no ensino podem ocorrer em determinados níveis e domínios e não acontecer em outros, uma vez que os grupos envolvidos com as atividades da disciplina não são homogêneos em relação a valores, interesses e identidades, mas formam dinamicamente "um 'movimento social' incluindo uma gama variável de 'missões' ou 'tradições' distintas representadas por indivíduos, grupos segmentos ou facções" (GOODSON, 1997, p. 44). Isso faz com que os padrões de mudança e de estabilidade disciplinar tenham que ser compreendidos como processos interdependentes e, portanto, podem ser investigados em materiais produzidos para o ensino, tendo em vista uma perspectiva teórico-metodológica com base sócio-histórica.

\section{Livros didáticos como fontes de pesquisa sócio-histórica}

A seleção e a análise dos livros didáticos têm como base, além dos estudos curriculares de Ivor Goodson (1983, 1996, 1997, 1998, 2001), os trabalhos de Macedo (2002), Le Goff (1985) e Nunes (1995) a respeito das fontes de pesquisa histórica. Investigações sobre a construção social dos currículos requerem enfoques metodológicos que permitam múltiplos olhares sobre uma grande complexidade de aspectos. A análise dos conhecimentos de natureza ecológica no contexto da disciplina escolar Ciências tem como principais fontes os livros didáticos considerados em suas relações temporais com as produções coletivas de diversos grupos, tanto do campo educacional quanto do campo da ecologia biológica, além dos aspectos socioambientais.

Os livros didáticos são compreendidos como produções escolares que expressam os sentidos das práticas curriculares, bem como produzem significados sobre as definições do que se ensina, de como se ensina e de qual formação docente deve ser desenvolvida. Esses materiais resultam de uma complexa estrutura de produção e de significação que abrange variadas instâncias dos sistemas educacionais (GVIRTZ et al., 2002; SELLES; FERREIRA, 2004). Considerando-se esses aspectos, os livros são investigados como construções curriculares que resultam de diversos contextos, tais como o governo e os órgãos oficiais, as instituições de ensino superior, seus autores, suas editoras e, ainda, os coordenadores, professores e alunos que os escolhem, adotam e usam, ressignificando-os durante as atividades escolares.

Nessa perspectiva, os livros didáticos selecionados como fontes de pesquisa foram organizados em dois conjuntos. No primeiro (quadro 1) foram analisados: (i) a coleção de quatro livros publicados nas décadas de 1970 e 1980 (Ciência para o mundo moderno); e (ii) um livro publicado nas décadas de 1960, 1970 e 1980 (Iniciação à ciência). Já no segundo conjunto (quadro 2) foram tomados para análise: (iii) dezoito livros didáticos de C. Barros, pertencentes a um total de sete coleções publicadas entre as décadas de 1970 e $2000 ;^{1}$ e (iv) dezenove livros didáticos de P. M. Silva e S. R. Fontinha, com a participação de T. Michael, compondo cinco coleções completas e uma incompleta publicadas entre as décadas de 1970 e 1990. Todos esses materiais foram analisados como fontes de sentidos de ecologia, de ciência e de ensino de Ciências. ${ }^{2}$

1- Procuramos entender os livros de Carlos Barros como recortes de diversas coleções, uma vez que não foi possível encontrar suas edições completas do período investigado.

2- Os livros didáticos apresentados nos quadros 1 e 2 são numerados de 1 a 30. Tal numeração é utilizada ao longo do texto para identificar os livros citados como fontes de dados para a pesquisa. 
Quadro $1-1^{\circ}$ conjunto de livros didáticos analisados

1. FROTA-PESSOA, 0.; GEVERTZ, R.; SILVA, A. G. Ciência para o mundo moderno: iniciação à ciência 5, para a $5^{\mathrm{a}}$ série do ensino de primeiro grau (antiga $1^{\text {a }}$ série ginasial). São Paulo: Companhia Editora Nacional, 1972.

2. FROTA-PESSOA, 0.; GEVERTZ, R. Ciência para o mundo moderno: iniciação à ciência 6, a vida na fazenda, $1^{\circ}$ grau. Rio de Janeiro: Livraria Francisco Alves Editora S.A., 1975.

3. FROTA-PESSOA, 0.; ARATANGY, L. R.; WIDMAN, J. Ciência para o mundo moderno: você e a vida 7, $1^{\circ}$ grau. Rio de Janeiro: Livraria Francisco Alves Editora S.A., 1976 .

4. FROTA-PESSOA, O.; ARATANGY, L. R.; SANTINI, M. A.; WILNER, E. Ciência para o mundo moderno: as profissões 8, $1^{\circ}$ grau. Rio de Janeiro: Livraria Francisco Alves Editora S.A., 1987.

5. FROTA-PESSOA, 0.; GEVERTZ, R.; SILVA, A. G. Como ensinar ciências: atualidades pedagógicas. v. 104. São Paulo: Companhia Editora Nacional; Editora da Universidade de São Paulo, 1970.

6. Dois exemplares de: VIEIRA, C. 0. F.; VIEIRA, N. B. P.; SILVA, W. de M. V. Cadernos MEC: iniciação à ciência 1. 2. ed. Brasilia: Ministério da Educação e Cultura; FENAME (Fundação Nacional de Material Escolar), 1970; e Iniciação à ciência. 5. ed., 2. tiragem. Rio de Janeiro: FAE (Fundação de Assistência ao Estudante), Ministério da Educação, 1987. Nesse último exemplar são indicadas todas as edições publicadas da obra: 1aa $2^{\mathrm{a}}, 3^{\mathrm{a}}, 4^{\mathrm{a}}, 5^{\mathrm{a}}$ ed.; 1969, 1971, $1973,1978,1984$ (1 $1^{\text {a }}$ tiragem).

Quadro $2-2^{\circ}$ conjunto de livros didáticos analisados

7. BARROS, C. 0 corpo humano: programa de saúde, $1^{\circ}$ grau. São Paulo: Editora Ática, 1976; Livro de atividades, 1977.

8. BARROS, C. Ciências, ar, água, solo, ecologia, universo, programas de saúde, 5 a série. São Paulo: Editora Ática, 1982 (acompanhado de um livro do professor). 9. BARROS, C. Os seres vivos, programas de saúde, ecologia, $1^{\circ}$ grau. São Paulo: Editora Ática, 1984 (acompanhado de um livro do professor).

10. BARROS, C. Química \& física, $1^{\circ} \mathrm{grau}$, Livro do Professor. São Paulo: Editora Ática, 1984.

11. BARROS, C. 0 corpo humano: programas de saúde, $1^{\circ} \mathrm{grau}$, Livro do Professor. São Paulo: Editora Ática, 1988.

12. BARROS, C. Alterando o ambiente: ar/água/solo/clima, recursos naturais, programas de saúde, ecologia, $5^{a}$ série. De acordo com 0 Guia Curricular do Estado de São Paulo. São Paulo: Editora Ática, 1980 (de acordo com a biblioteca em que foi copiado).

13. BARROS, C. Ciências: meio ambiente, ecologia, programas de saúde, $5^{a}$ série. São Paulo: Editora Ática, 1992 (acompanhado de dois cadernos de atividades, 1990, 1992).

14. BARROS, C. Os seres vivos: ecologia e programas de saúde. São Paulo: Editora Ática, 1991, 1994, 1996 (acompanhado de um caderno de atividades, 1991). 15. BARROS, C. $O$ corpo humano: programas de saúde. São Paulo: Editora Ática, 1990, 1991, 1992, 1992, 1994 (acompanhado de três cadernos de atividades, 1990, 1992, 1992).

16. BARROS, C. Física e química. São Paulo: Editora Ática, 1991, 1994, 1994 (acompanhado de dois cadernos de atividades, 1991, 1992)

17. BARROS, C.; PAULINO, W. R. Ciências: o meio ambiente, 5a série, livro do professor. São Paulo: Editora Ática, 1997, 2001.

18. BARROS, C.; PAULINO, W. R. O corpo humano: ciências - 7a série. São Paulo: Editora Ática, 2002.

19. BARROS, C.; PAULINO, W. R. Física e química: livro do professor. São Paulo: Editora Ática, 2000.

20. BARROS, C.; PAULINO, W. R. Ciências: o meio ambiente, 5a série, manual do professor. 2. ed., 1. reimp. São Paulo: Editora Ática, 2002 (PNLD 2005).

21. BARROS, C.; PAULINO, W. R. Ciências: o meio ambiente, $5^{a}$ série, livro do professor. São Paulo: Editora Ática, 2002.

22. BARROS, C.; PAULINO, W. R. Ciências: os seres vivos, 6a série, manual do professor. 2. ed., 1. reimp. São Paulo: Editor Ática, 2002 (PNLD 2005).

23. BARROS, C.; PAULINO, W. R. Ciências: 0 corpo humano, $7^{\text {a }}$ série, manual do professor. 2. ed. São Paulo: Editora Ática, 2002 (PNLD 2005).

24. BARROS, C.; PAULINO, W. R. Física e química: ciências, 8a série, livro do professor. 2. ed. São Paulo: Editora Ática, 2002.

25. SILVA, P. M.; FONTINHA S. R. Ciências no $1^{0}$ grau, v. 1: a Terra - seus ambientes e seus habitantes, 5. ed., 1976; 2. ed., 1977; 3. ed., 1979 (acompanhado de caderno de atividades, edição 1979, e guia do professor, edição 1978); Ciências no $1^{\circ}$ grau, v. 2: os seres vivos - como são e onde vivem, 3. ed., 1976; 6. ed., 1979; Ciências no $1^{\circ}$ grau, v. 3: o homem - sua biologia e sua ecologia, 1975 (acompanhado de caderno de atividades, edição 1976); Ciências no $1^{\circ}$ grau, v. 4: química/física - seus fundamentos, suas aplicações, 4. ed., 1977. São Paulo: Companhia Editora Nacional. 26. SILVA, P. M.; FONTINHA S. R. Ciências no $1^{\circ} \mathrm{grau}$, v. 2: as substâncias, no laboratório, na vida, na natureza, 1977; Ciências no 1ํ grau, v. 7: a energia, formas, transformações e usos, 1978; Ciências no $1^{\circ}$ grau, v. 8: a espécie humana, passado, presente e futuro, 1979. São Paulo: Companhia Editora Nacional.

27. SILVA, P. M.; FONTINHA S. R.; MICHAEL, T. Ciências 1: a Terra, um ponto no espaço; meio ambiente, saúde, ecologia, (sem data); Ciências 2: seres vivos, os habitantes da terra, zoologia, botânica, saúde, ecologia, (sem data, acompanhado de caderno de atividades); Ciências 3: o homem, seu corpo e suas funções; 0 corpo humano, saúde, ecologia (sem data, acompanhado de caderno de atividades). São Paulo: Companhia Editora Nacional (segundo depoimento do professor Fontinha, o volume 4 continuou o mesmo livro da década de 1970 sem reformulações).

28. SILVA, P. M.; FONTINHA S. R. Ciências, $1^{\circ}$ grau, v. 1: Terra e vida, (sem data); Ciências, $1^{\circ}$ grau, v. 2: a biodiversidade, (sem data); Ciências, $1^{\circ}$ grau: v. 3: a espécie humana, (sem data); Ciências, $1^{\circ}$ grau, v. 4: matéria e energia em transformação, (sem data). São Paulo: Companhia Editora Nacional. 29. SILVA, P. M.; FONTINHA S. R. Ciências, v. 1, (sem data); v. 2., (sem data); v. 3., (sem data); v. 4.; (sem data). São Paulo: Companhia Editora Nacional. 30. SILVA, P. M.; FONTINHA S. R., Ambiente, componentes e interações: ciências, ensino fundamental, v. 2, 6a série. São Paulo: Companhia Editora Nacional, 1996 (PNLD 1999). 
Os livros do primeiro conjunto valorizam predominantemente atividades e conteúdos relacionados a experimentos e ao cotidiano. Além disso, são obras em que o formato editorial e a apresentação dos conteúdos têm muitas semelhanças com materiais didáticos produzidos anteriormente a 1970, conforme indicado por Gomes (2008) em sua análise sobre livros didáticos de Ciências do período entre 1930 e 2000. Diferentemente, o segundo conjunto de livros apresenta a ecologia em disputa com outros enfoques curriculares do ensino de Ciências. Os livros desse segundo conjunto são de tamanho maior e já apresentam figuras coloridas, características editoriais semelhantes às dos livros atuais.

A importância de todos esses livros didáticos se justifica por sua circulação expressiva e pela relevância de seus autores na história do ensino de Ciências no Brasil. As obras do quadro 1 (1 a 6) são representantes de propostas curriculares produzidas durante o movimento de renovação do ensino de Ciências no período entre o final da década de 1950 e a década de 1970 (BARRA; LORENZ, 1986; LORENZ, 2004). Os autores desses livros foram lideranças em tal movimento, divulgando suas ideias e orientações curriculares, o que é evidenciado por sua relação com importantes instituições ligadas ao ensino de Ciências nesse período, como os Centros de Ciências (GOMES, 2008).

Já os livros do quadro 2 (7 a 30) passaram a circular no cenário do ensino da disciplina a partir dos anos 1970, quando a produção editorial de livros didáticos no Brasil inicia sua expansão. Além disso, o Professor S. R. Fontinha participava das atividades de formação continuada do CECIGUA (Centro de Ciências da Guanabara), um dos espaços institucionais representativos do movimento renovador, tendo, portanto, continuado sua formação de professor de Ciências sob tal influência (GOMES, 2008).

Entretanto, isso não significa que essa amostra seja capaz de refletir todos os livros didáticos produzidos durante o período investigado, tampouco todas as propostas curriculares apresentadas ao longo desses anos. Não há, na análise realizada, a pretensão de abranger todas as possibilidades de significação do currículo de Ciências no período, mesmo no que concerne apenas à abordagem dos conhecimentos ecológicos.

Esses materiais são considerados como documentos/monumentos, frutos de sua época, nos quais estão inscritas as tradições culturais e sociais representativas dos grupos que participaram de sua produção (LE GOFF, 1985). Além disso, numa perspectiva de articulação teórico-metodológica característica da produção de conhecimentos nas pesquisas históricas, os livros são tratados de forma a articular relacionalmente a teoria e a análise (NUNES, 1995). Essa perspectiva de articulação fundamenta a estruturação de eixos de leitura, interpretação e significação das fontes de pesquisa, e a partir dela são criadas as categorias de análise e feita a organização da escrita dos resultados construídos. Assim, são elaborados dois eixos de leitura e interpretação dos significados curriculares dos conteúdos: (i) os enfoques curriculares do ensino de Ciências; e (ii) a produção dos conteúdos de ensino dessa disciplina nas quatro séries do nível de ensino, que se aproximam hoje do segundo segmento do ensino fundamental.

No primeiro eixo, os enfoques organizadores do currículo representam os fios condutores da seleção, da distribuição e da organização dos conteúdos de ensino assumidos pelos autores. Incluem-se tanto as proposições para o ensino de Ciências expressas nos textos de apresentação aos professores e estudantes, quanto sua expressão na produção dos conteúdos de ensino. Nos livros didáticos, é possível identificar e analisar os enfoques organizadores do currículo que vêm fazendo parte da história do ensino de Ciências no Brasil, tais como: a história natural; a ecologia; a anatomia, fisiologia e saúde humanas; a ciência e a experimentação; a ciência e a tecnologia; e a vida cotidiana. Tais enfoques podem ser vislumbrados a partir de relações entre os conteúdos selecionados e as finalidades para 
a formação dos alunos. Essas relações inserem os enfoques organizadores do currículo de Ciências identificados na pesquisa numa perspectiva educacional mais ampla, sendo possível afirmar que eles mesclam características de tradições utilitárias, pedagógicas e acadêmicas, como descrito por Goodson (1998). 0 quadro 3 apresenta as características de cada um dos enfoques curriculares identificados nos livros analisados.

Quadro 3 - Enfoques curriculares da disciplina Ciências nos livros didáticos analisados (GOMES, 2008)

\begin{tabular}{|c|c|}
\hline História natural & $\begin{array}{l}\text { Visões de ciência caracterizadas por descrições detalhadas, coleções e classificações do mundo natural (vivo e não } \\
\text { vivo), apresentando relações com a trajetória da zoologia, da botânica, da paleontologia, da mineralogia e da geologia; } \\
\text { visão evolutiva associada a tradições acadêmicas mais recentes da história da disciplina científica biologia; coleções, } \\
\text { contar histórias do mundo natural. }\end{array}$ \\
\hline Ecologia & $\begin{array}{l}\text { Duas perspectivas: (i) percepções de ciência e seu ensino, referenciadas na ecologia do campo biológico com seus } \\
\text { métodos de trabalho, incluindo tanto os conhecimentos da ecologia de populações e comunidades, quanto os da } \\
\text { ecologia de ecossistemas (VIEIRA, 2003); e (ii) percepções relacionadas a movimentos ambientalistas, principalmente } \\
\text { aqueles relacionados à educação ambiental com finalidade de promover nos estudantes interesse pelas problemáticas } \\
\text { ambientais; pode aparecer associado a tradições tanto acadêmicas quanto pedagógicas e/ou utilitárias; pode } \\
\text { sobrepor-se à história natural, à qualidade de vida e à saúde. }\end{array}$ \\
\hline $\begin{array}{l}\text { Anatomia, fisiologia } \\
\text { e } \\
\text { saúde humanas }\end{array}$ & $\begin{array}{l}\text { Conhecimentos sobre corpo humano, saúde e expectativa de vida; valorização de características e causas de doenças } \\
\text { ou da importância da saúde e da qualidade de vida; inclui aspectos sociais associados a aspectos da saúde e do } \\
\text { bem-estar; integra um caráter acadêmico a aspectos pedagógicos e utilitários. }\end{array}$ \\
\hline $\begin{array}{l}\text { Ciência } \\
\text { e experimentação }\end{array}$ & $\begin{array}{l}\text { Método científico experimental como principal característica da ciência, valorizando as etapas que devem ser } \\
\text { cumpridas tanto para a produção do conhecimento científico, quanto para a aprendizagem das ciências; versões } \\
\text { de experimentação e método científico relativas a diversos campos científicos; vínculo a uma tradição acadêmica } \\
\text { mesclada com tradições de natureza pedagógica a partir das versões escolares de experimentação. }\end{array}$ \\
\hline $\begin{array}{l}\text { Ciência } \\
e \\
\text { tecnologia }\end{array}$ & $\begin{array}{l}\text { Visões de ciência vinculadas à produção tecnológica, que influencia e modifica social e economicamente a vida dos } \\
\text { seres humanos; é originário de tradições acadêmicas, mas aparece com perspectivas utilitárias. }\end{array}$ \\
\hline Vida cotidiana & $\begin{array}{l}\text { Concepções de ciência e de ensino de ciências relacionadas a aspectos da vida cotidiana: vida doméstica e atividades } \\
\text { profissionais; perspectivas de tradições utilitárias e pedagógicas. }\end{array}$ \\
\hline
\end{tabular}

Quadro 4 - Enfoques curriculares nos livros didáticos (GOMES, 2008)

\begin{tabular}{|c|c|}
\hline Materiais analisados & Enfoques \\
\hline $\begin{array}{l}\text { Livros } 1 \text { a } 5 \text { : } \\
\text { FROTA-PESSOA, 0. e outros autores } \\
\text { Décadas de 1970-1980 }\end{array}$ & 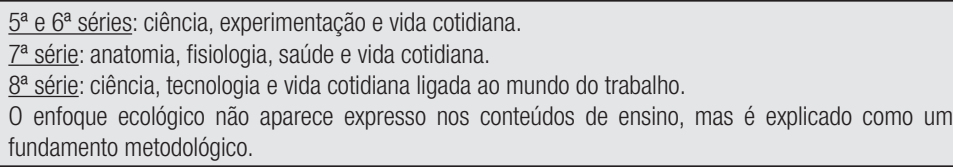 \\
\hline $\begin{array}{l}\text { Livro 6: } \\
\text { VIEIRA, C. O. F.; VIEIRA, N. B. P.; SILVA, W. } \\
\text { M. V. } \\
\text { Décadas de } 1970-1980\end{array}$ & $\begin{array}{l}\text { Livro único: história natural na unidade I, referente aos conteúdos de biologia; ciência e experimentação } \\
\text { nas unidades II e III, referentes aos conteúdos de física e química. } \\
\text { Sem enfoque ecológico. }\end{array}$ \\
\hline $\begin{array}{l}\text { Livros } 7 \text { a } 24 \text { : } \\
\text { BARROS, C. } \\
\text { Décadas de } 1970-2000\end{array}$ & $\begin{array}{l}\text { 5a série: ciência, experimentação, vida cotidiana e ecologia. } \\
\text { 6a série: história natural, ecologia. } \\
\text { 7a série: anatomia, fisiologia e saúde; sem enfoque ecológico. } \\
\text { 8a série: ciência, tecnologia, cotidiano, experimentação; sem enfoque ecológico. } \\
\text { Enfoque ecológico expresso nos conteúdos de ensino; ecologia dos ecossistemas inserida em capítulos } \\
\text { separados. }\end{array}$ \\
\hline $\begin{array}{l}\text { Livros } 25 \text { a 30: } \\
\text { SILVA, P. M.; FONTINHA, S. R. } \\
\text { Décadas de 1970-1990 }\end{array}$ & 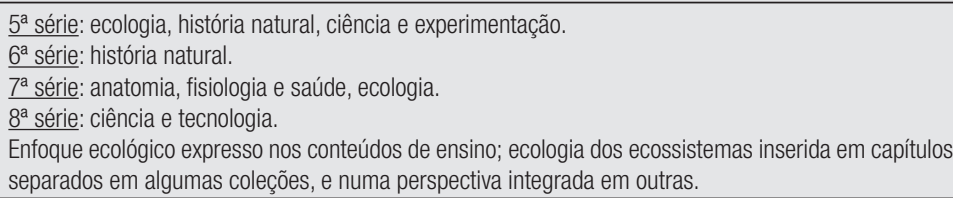 \\
\hline
\end{tabular}


Quadro 5 - Distribuição de conteúdos de ensino nas séries (GOMES, 2008)

\begin{tabular}{|c|c|}
\hline Materiais analisados & Conteúdos nas séries \\
\hline $\begin{array}{l}\text { Sumários dos livros } 1 \text { a } 5: \\
\text { FROTA-PESSOA, 0. e outros autores. } \\
\text { Décadas de 1970- } 1980\end{array}$ & $\begin{array}{l}\text { 5a série: ar, água, luz, som, eletricidade, rádio, televisão, matéria, peso, volume, densidade, } \\
\text { máquinas simples, energia e suas transformações, meios de transporte, viagem à lua. } \\
\text { 6asérie: plantas, chuva, vento, estações do ano, fogo, animais, alimentos e energia, doenças e } \\
\text { saúde no Brasil. } \\
\text { na série: a primeira infância, a infância, nutrição, doenças da infância, adolescência, puberdade, } \\
\text { namoro, coordenação nervosa, a vida adulta, células, herança biológica, gravidez. } \\
\text { 8 série: profissão, mercado de trabalho, cursos técnicos, mecânica de automóveis, eletricidade, } \\
\text { eletrônica, computação, enfermagem. } \\
\text { Sem conteúdos de ensino relacionados ao enfoque ecologia. }\end{array}$ \\
\hline $\begin{array}{l}\text { Sumário do livro 6: } \\
\text { VIEIRA, C. O. F.; VIEIRA, N. B. P.; SILVA, } \\
\text { W. M. V. } \\
\text { Décadas de } 1970-1980\end{array}$ & $\begin{array}{l}\text { Livro único: unidade I-Biologia: os animais, as plantas e seus problemas da vida e da } \\
\text { sobrevivência; unidade II-Química: De que são formadas as coisas; unidade III-Física: Os } \\
\text { átomos não estão parados. } \\
\text { Sem conteúdos de ensino relacionados ao enfoque ecologia. }\end{array}$ \\
\hline $\begin{array}{l}\text { Temáticas que predominam entre os } \\
\text { conteúdos dos livros } 7 \text { a } 24: \\
\text { BARROS, C. } \\
\text { Décadas de } 1970-2000\end{array}$ & 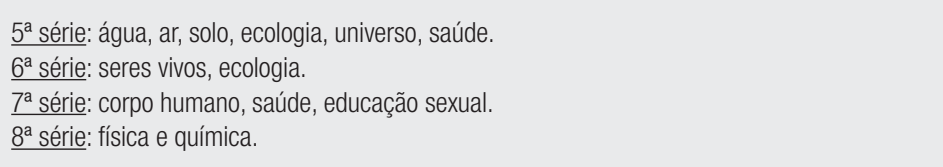 \\
\hline $\begin{array}{l}\text { Temáticas que predominam entre os } \\
\text { conteúdos dos livros } 25 \text { a } 30: \\
\text { SILVA, P. M.; FONTINHA, S. R. } \\
\text { Décadas de 1970-1990 }\end{array}$ & 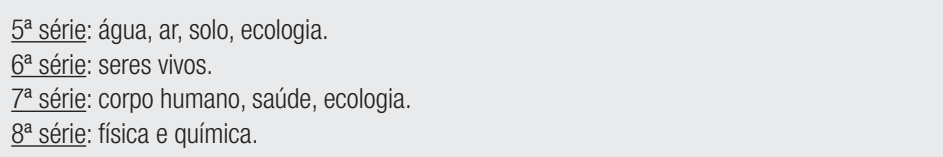 \\
\hline
\end{tabular}

0 segundo eixo de investigação inclui a análise da produção dos conteúdos de ensino nas quatro séries finais do ensino fundamental. São identificadas as séries em que os conhecimentos de natureza ecológica aparecem nos livros didáticos, procurando entender não apenas os padrões dessa distribuição que se mantêm ao longo das quatro séries, mas também as mudanças ocorridas durante o período histórico estudado. Essa estratégia foi empregada para compreender como se dá a organização dos conteúdos em cada série e seus padrões de estabilidade e mudança (GOODSON, 1997).

\section{Estabilidade e mudança nos livros didáticos de Ciências}

As análises dos sumários, das apresentações, dos objetivos e dos planos de ensino presentes nos manuais dos professores e nos capítulos dos livros didáticos possibilitaram identificar um arcabouço comum de enfoques curriculares (quadro 4) e de distribuição de conteúdos pelas séries (quadro 5).

A estruturação do que e do como ensinar proposta nesses materiais forma um conjunto padronizado de enfoques e conteúdos relacionados às finalidades do ensino de Ciências que vêm sendo construídas pelos grupos sociais envolvidos com essa disciplina desde os anos de 1930. Os debates e as propostas que oficializaram a disciplina escolar Ciências na Reforma Francisco Campos (BRASIL, 1931) caracterizavam-se por uma orientação integradora de temáticas relacionadas a diversos campos científicos, tais como a biologia, a física, a química e a geologia. Nesse sentido, Venâncio Filho (1940) defendeu, em 1932, os elementos constituintes de um programa para a disciplina Ciências a partir de princípios fundamentais baseados na integração e no caráter experimental dos estudos sobre o ar, a água, a terra, a energia, a vida e a civilização em suas perspectivas físicas, químicas, cósmicas, biológicas e sociais. 
0 ensino deveria considerar a interdependência dos componentes da natureza, atentando aos princípios fundamentais de integração, com acesso direto e experimental às noções e aos fatos das Ciências. Deveriam ser consideradas também as experiências de vida das crianças, o sentido de harmonia e de beleza dos estudos sobre a natureza e, ainda, o sentido de solidariedade humana.

Tanto os princípios fundamentais quanto as temáticas gerais apresentadas por Venâncio Filho são ressignificados nos enfoques curriculares e nos conteúdos dos livros analisados, datados das décadas de 1970 até 1990 . 0 quadro 4 apresenta os enfoques curriculares com maior valorização. Os livros de $5^{\text {a }}$ série $^{3}$ têm por finalidade apresentar aos alunos a ciência e a experimentação, bem como as relações entre ciência e vida cotidiana, a partir de aspectos relacionados ao mundo natural, à vida doméstica, à promoção da saúde e ao meio ambiente. Já na $6^{a}$ série, o enfoque de história natural aparece fortemente na apresentação de conteúdos de ensino sobre os animais e as plantas. Os enfoques de $5^{\mathrm{a}}$ e $6^{\mathrm{a}}$ séries mesclam-se em algumas coleções, como é o caso dos livros de Frota-Pessoa para essas duas séries (livros 1 e 2) e de uma das coleções (25) de Silva e Fontinha, da década de 1970.

Os livros de 7a série caracterizam-se pela valorização do enfoque anatomia, fisiologia e saúde, com algumas variações entre os autores. Por exemplo, os livros de Frota-Pessoa (3) e Barros (7, 11, 15, 18 e 23) valorizam aspectos de saúde relacionados à educação sexual e à vida na adolescência, contextualizando socialmente a biologia reprodutiva. Já os de Silva e Fontinha (volumes destinados a essa série, das coleções 25, 26, 27, 28 e 29) apresentam uma associação entre os enfoques saúde e ecologia. Por fim, os livros de $8^{\text {a }}$ série em geral apresentam aspectos tecnológicos dos campos da Física e da Química. No livro de Frota-Pessoa para

3 - Fazemos referências a $5^{\mathrm{a}}, 6^{\mathrm{a}}, 7^{\mathrm{a}}$ e $8^{\mathrm{a}}$ séries e não aos correspondentes atuais $6^{\circ}, 7^{\circ}, 8^{\circ}$ e $9^{\circ}$ anos da escolaridade por serem os materiais analisados anteriores à denominação em vigor na atualidade para o ensino fundamental. essa série (4), a abordagem é feita a partir da apresentação de profissões. 0 livro de Vieira, Vieira e Silva (6) é o que mais se diferencia dos demais, sendo uma publicação única para a qual não há indicação de série. Apresenta como principais enfoques a história natural e a ciência e experimentação, aproximando-se do padrão geral de $5^{\mathrm{a}}$ e $6^{\mathrm{a}}$ séries dos livros analisados de outros autores.

No que diz respeito à distribuição de conteúdos pelas quatro séries, o quadro 5 também mostra um padrão com semelhanças entre os autores no período entre as décadas de 1970 e 2000. Há diferenças entre os autores, mas há um padrão que mantém proximidade com a maior parte das temáticas propostas por Venâncio Filho relacionadas ao estudo de aspectos físicos, químicos e biológicos dos componentes da natureza: a água, o ar e o solo. No caso das coleções didáticas de Barros e Silva e de Fontinha, a distribuição de conteúdos de ensino pelas quatro séries evidencia o padrão, presente em todo o período. Nessas coleções, para a 5 a série, é proposto o ensino de conteúdos mais relacionados ao planeta Terra, como a água, o ar e o solo, os quais têm suas referências científicas nos campos da Biologia, da Física, da Química, da Geologia e da Astronomia. Já na 6a série, são apresentados os seres vivos, muito ligados ao campo biológico de conhecimentos. Por sua vez, na $7^{\text {a }}$ série, os livros didáticos apresentam conteúdos de ensino relativos ao corpo humano, abordando conhecimentos relacionados à Anatomia e à Fisiologia. Por fim, na $8^{\text {a }}$ série, são privilegiados conteúdos de ensino da Física e da Química.

Portanto, os livros didáticos mostram um arcabouço característico de organização da disciplina Ciências desde sua inserção nos currículos pela Reforma de Francisco Campos na década de 1930. Esse arcabouço pode ser compreendido como expressão de um padrão de estabilidade (GOODSON, 1997) da disciplina Ciências, resultando de forças que operam na evolução sócio-histórica do currículo disciplinar. Os livros didáticos apresentam-se organizados dentro de um padrão estável expresso 
nos enfoques curriculares e na distribuição de conteúdos pelas séries. Essa estabilidade contribui para a naturalização dos conteúdos de ensino, fazendo com que pareçam imutáveis.

No que diz respeito aos conhecimentos ecológicos, a ecologia representa um enfoque curricular metodológico, ainda que a ecologia referenciada no campo biológico não esteja entre os conteúdos de ensino nos livros de Frota-Pessoa e outros autores ( 1 a 5). Assim, o enfoque ecológico não é expresso nos conteúdos, mas é explicado como um fundamento metodológico, voltado para as relações sociais harmoniosas que propiciam processos ativos de aprendizagem. Nos livros de Barros e de Silva e Fontinha (7 a 30), a ecologia é inserida como enfoque curricular expresso em conteúdos de ensino. Com base em todos os materiais didáticos analisados, é possível afirmar que, a partir da década de 1970, circulavam livros didáticos que valorizavam a ecologia sob a forma de conteúdos de ensino, mas também havia aqueles materiais em que essa temática era considerada metodologicamente. Ao lado desses, ainda havia os que não valorizavam a ecologia, como o livro de Vieira, Vieira e Silva (6).

Os livros didáticos de Ciências, tendo a ecologia como enfoque curricular expresso em conteúdos de ensino a partir da década de 1970, podem ser considerados representantes de uma mudança construída num arcabouço padronizado de enfoques curriculares em diálogo entre si e com finalidades educacionais acadêmicas, utilitárias e pedagógicas. Os livros didáticos analisados apresentam esse arcabouço a partir de uma integração de conteúdos de ensino que se expressam como padrões estáveis nas temáticas das quatro séries finais do ensino fundamental, respectivamente: ar, água e solo; seres vivos; anatomia e fisiologia humana; física e química. A ecologia pode então ser interpretada como mudança no contexto do movimento de renovação ocorrido entre as décadas de 1950 e 1970 (BARRA; LORENZ, 1986; LORENZ, 2004). Esse movimento, tendo como principal argumento a experimentação para a melhoria do ensino de Ciências, possibilitou espaços curriculares para o fortalecimento de outras abordagens e visões de ensino, como a ecologia.

Goodson (1997) avalia que alterações no padrão disciplinar exigem uma ocorrência de concordância sobre as mudanças em espaços sociais internos e externos à escola e envolvem os atores sociais de grupos e subgrupos disciplinares que atuam na produção curricular. Nesse sentido, é importante citar que, durante os anos de 1970, os autores Silva e Fontinha publicaram uma segunda coleção (26) baseada numa outra lógica temática que não seguia o padrão geral apresentado nos quadros 4 e 5 . A coleção era baseada em temas gerais, como as substâncias, a energia e a espécie humana, mas não continuou sendo publicada pela editora porque, segundo o professor Fontinha, ${ }^{4}$ a referida coleção, mesmo sendo sua preferida, não atendeu às expectativas dos professores. 0 fato de esses livros não terem sido julgados adequados para a prática escolar pode ser considerado um dos mecanismos mantenedores de padrões de ensino na disciplina Ciências.

É nesse sentido que Goodson (1996, 1997) identifica os sistemas educacionais como produtores de padrões socialmente legítimos de professores, alunos, temas e atividades, uma vez que são esses sistemas que propiciam condições ideológicas e materiais para as disciplinas escolares e seus profissionais. Por isso, a criação de retóricas pelas comunidades disciplinares inclui a apropriação desses padrões, pois as demandas sociais, as instituições escolares e seus atores são interdependentes nas decisões e ações curriculares. Dessa forma, determinadas retóricas sobre as disciplinas escolares são mantidas ou modificadas, associando interesses materiais, idealistas e morais às comunidades disciplinares. É assim que as disciplinas escolares vão se tornando naturalizadas, parecendo inquestionáveis, deixando as mudanças pouco visíveis e, portanto, aparecendo como monólitos mitificados.

4 - Depoimento do professor Fontinha concedido a Maria Margarida Gomes em 15 de junho de 2007. 
Entretanto, as disciplinas escolares mudam, mas de forma subjacente aos mecanismos que promovem a estabilidade. A força desse processo de mudança está relacionada aos desencontros acerca de finalidades educacionais entre estruturas internas e externas às disciplinas. Quando os grupos sociais que atuam internamente às disciplinas entram em acordo com demandas sociais e educacionais dos meios externos, viabiliza-se a mudança curricular. Isso porque, em geral, segundo Goodson (1997), são as estruturas externas que vão criar os padrões de valorização do que deve ou não ser ensinado às gerações mais jovens. De acordo com essa argumentação, a valorização dos conhecimentos ecológicos pelos grupos de profissionais envolvidos com a disciplina Ciências não seria suficiente para que viessem a se tornar tão importantes nos currículos dessa disciplina. Tal importância se deve a uma coordenação não somente com interesses científicos - com o fortalecimento da ecologia -, mas também com questões educacionais e sociais. Além disso, a educação ambiental começava a aparecer no cenário internacional na década de 1970, como resultado de discussões em torno de problemáticas ambientais relacionadas ao modelo de desenvolvimento econômico mundial.

A análise dos enfoques curriculares e dos conteúdos de ensino dos livros didáticos nos permite concluir quanto à existência de padrões de estabilidade na disciplina Ciências. Esses padrões de estabilidade são mesclados a mudanças perceptíveis capazes de, ao mesmo tempo, garantir a continuidade da disciplina e possibilitar transformações a partir de questões cotidianas e sociais relevantes. Esse é o caso do enfoque ecológico nos livros didáticos tanto de Barros quanto de Silva e Fontinha, que têm um caráter de mudança, mas são marcados pelas interligações estabelecidas com enfoques curriculares já presentes nesses materiais antes da década de 1970.

No caso dos livros didáticos de Barros (7 a 24) e de Silva e Fontinha (25 a 30), a relação entre a mudança para um novo enfoque e a continuidade de enfoques já existentes no ensino de Ciências se dá de duas formas: uma abordagem que apresenta a ecologia a partir de capítulos separados e uma perspectiva mais integrada da ecologia a outros conteúdos de ensino. Todas as coleções de Barros (7 a 24) e duas coleções de Silva e Fontinha das décadas de 1980 (27) e 1990 (29) apresentam o enfoque ecológico em capítulos separados. Esses últimos autores, contudo, têm duas coleções das décadas de 1970 (25) e de 1990 (28) que apresentam uma abordagem integrada, a partir de deslizamentos entre uma ecologia voltada para questões sociais, como o meio ambiente e a saúde, e uma referenciada em conhecimentos acadêmicos da ecologia do campo biológico. Assim, por exemplo, na década de 1970, o ciclo de materiais é apresentado para a compreensão das relações entre os grupos de seres vivos na natureza, indicando esta como um sistema que depende das adaptações de todos os seus componentes:

\section{O vaivém das substâncias \\ Atribui-se a Lavoisier (o mesmo que você conheceu no capitulo 3) a expressão "na natureza nada se cria, nada se perde, tudo se transforma". Quanta verdade nesta frase! Basta lembrarmos que um certo material que hoje está no solo, amanhã pode estar numa goiaba, depois de amanhã num pássaro, e no outro dia transformado novamente em solo. Se não fosse assim, um dia as plantas não poderiam fabricar mais alimento, os animais morreriam de fome e toda a vida na Terra se extinguiria. (25, v. 1, p. 95)}

0 texto $O$ vaivém das substâncias também exprime uma estratégia pedagógica que visa à integração do conceito de ciclo dos materiais na natureza com outros conteúdos estudados anteriormente relativos a Lavoisier ${ }^{5} \mathrm{e}$ também a temáticas relacionadas à saúde do ambiente e do ser humano.

5- Cabe mencionar que se trata de uma visão substancialista (LOPES, 2007), na medida em que, quimicamente, não são as substâncias/materiais que vêm e vão, mas elementos químicos. 
0 mesmo conceito de ciclo dos materiais representa uma indicação de que a natureza do planeta Terra é um conjunto equilibrado, tal como diz a mensagem ao leitor de um livro de $5^{\text {a }}$ série da década de 1990:

Este livro se compõe de seis partes. No começo de cada uma você encontra uma pequena mensagem para leitura e reflexão.

Mas a grande mensagem deste livro é que na natureza tudo se movimenta, nada está fixo. Pense nos exemplos que se seguem.

A água que hoje forma um rio, outro dia está no mar, no ar, num ser vivo, e nada impede que volte para um rio.

0 carbono que um dia está no ar, no outro faz parte de uma planta ou de um animal, porém, inevitavelmente, acaba voltando para o ambiente, recomeçando seu ciclo interminável.

A natureza não desperdiça nada. Tudo é reaproveitado em ciclos que não acabam nunca. Esses ciclos formam um conjunto de partes que se integram num equilíbrio maravilhoso, mas, ao mesmo tempo, delicado.

Preservando os ciclos da natureza estaremos contribuindo para preservar o equilíbrio em nosso planeta.

A Terra é viva!

Viva a Terra!

Paulo Maurício e Fontinha.

$(28$, v. 1, p. 3)

Assim, o ciclo de materiais pode servir ao propósito de ensinar a ideia de todo, de interdependência dos seres vivos, mostrando como os seres humanos são responsáveis pela manutenção desse ciclo que afeta a vida de todos os seres vivos no planeta Terra. Evidenciamos, ainda, que tanto nas coleções de Barros quanto nas de Silva e Fontinha os conteúdos de ensino são fortemente influenciados pelos estudos dos ecossistemas e por problemáticas ambientais.

\section{Considerações finais}

As perspectivas de Chervel (1990) e Julia (2001, 2002), bem como a de Goodson (1983, 1996, 1997, 1998, 2001), mostram o quanto os estudos históricos tornam compreensíveis as dinâmicas que produzem as disciplinas escolares. Conhecer como determinados conteúdos específicos se apresentam ao longo de um período histórico pode contribuir tanto para uma outra visão acerca dos acontecimentos internos às instituições escolares, quanto para melhor elucidar o conhecimento escolar em uma perspectiva de conhecimento suis generis.

A abordagem histórica parece potente para compreender mudanças na estrutura de estabilidade das disciplinas escolares, oferecendo contribuições de ordem teórica para a análise dos livros didáticos. Por exemplo, no presente estudo, ao priorizar os contextos que influenciam a produção dos materiais escolares e a diversidade de inter-relações entre as finalidades acadêmicas, utilitárias e pedagógicas na produção curricular, as perspectivas pedagógicas são valorizadas ao instituir novos sentidos para os conhecimentos referenciados nos contextos científicos e acadêmicos.

Nesse sentido, a investigação aqui apresentada visa fornecer contribuições não somente para a compreensão da história dos conhecimentos ecológicos em materiais didáticos destinados ao ensino de Ciências, mas também para produzir evidências ainda inexploradas sobre o tratamento didático dos conhecimentos ecológicos no período. A relevância teórica do trabalho se destaca no que diz respeito às estratégias de análise dos conteúdos de ensino, tratados como bases para a investigação da produção curricular numa disciplina escolar.

Os conteúdos dos livros didáticos são representações de modos de pensar e fazer o ensino de Ciências que se vêm integrando à sua história. Os enfoques curriculares identificados são expressões desses modos de pensar e fazer o ensino, desenvolvidos a partir do diálogo entre finalidades educacionais referenciadas tan- 
to no território da produção de conhecimentos dos campos científicos, quanto em contextos educacionais e cotidianos. Cada um desses enfoques - história natural; ecologia; anatomia, fisiologia e saúde humanas; ciência e experimentação; ciência e tecnologia; e vida cotidiana - expressa um conjunto complexo de finalidades de ensino, construídas sócio-historicamente em diálogos entre tradições de ensino acadêmicas, utilitárias e pedagógicas.

A partir da análise desses diálogos, o trabalho indica que a disciplina Ciências pode ser entendida a partir de processos interdependentes de estabilidade e mudança, tal como proposto por Ivor Goodson (1997). Reconhece-se um padrão de estabilidade na disciplina escolar Ciências desde sua oficialização durante os debates da Reforma Francisco Campos (BRASIL, 1931). Igualmente se identifica a ecologia como uma mudança, entre as décadas de 1970 e 1990, que se apresenta na valorização da integração curricular no ensino de Ciências e de conteúdos e valores relacionados à harmonia e à interdependência dos componentes da natureza. Dessa forma, é possível compreender, conforme Goodson (1983, 1996, 1997, 1998, 2001), as dinâmicas constituintes dessa disciplina escolar.

A discussão apresentada aponta para a continuidade do trabalho a partir de investigações que ampliem a amostra de livros didáticos aqui investigada, analisando a relação dos autores desses materiais com a história da disciplina Ciências e do pensamento ecológico. Tais perspectivas futuras podem contribuir para aprofundar a compreensão dos sentidos atribuídos ao enfoque curricular da ecologia e suas relações com as outras temáticas valorizadas nessa disciplina escolar. 


\section{Referências}

BARRA, Vilma Marcassa; LORENZ, Karl M. Produção de materiais didáticos de ciências no Brasil, período: 1950 a 1980. Ciência e Cultura, v. 38, n. 12, p. 1970-1983, 1986.

BRASIL, Ministério da Educação e Saúde Pública. Exposição de Motivos da Reforma Campos e Decreto 19.890 de abril de 1931. In: Organização do Ensino Secundário. Rio de Janeiro: Imprensa Nacional, 1931.

CHERVEL, André. História das disciplinas escolares: reflexões sobre um campo de pesquisa, Teoria \& Educação, Porto Alegre, ก. 2, 1990.

GOMES, Maria Margarida. Conhecimentos ecológicos em livros didáticos de ciências: aspectos sócio-históricos de sua constituição. Tese (Doutorado) - Universidade Federal Fluminense, Niterói, 2008.

GOODSON, Ivor F. School subjects and curriculum change: case studies in curriculum history. Londres; Canberra: Croom Helm, 1983.

A construção social do currículo. Lisboa: EDUCA, 1997.

Currículo: teoria e história. Petrópolis: Vozes, 1998.

0 currículo em mudança. Porto: Porto Editora, 2001.

GOODSON, Ivor F;; MARSH, Colin J. Studying school subjects: a guide. Londres: Falmer Press, 1996.

GVIRTZ, Silvina et al. A politização do currículo de ciências nas escolas argentinas (1870-1950). In: LOPES, Alice Casimiro; MACEDO, Elizabeth (Orgs.). Disciplinas e integração curricular: histórias e políticas. Rio de Janeiro: DP\&A, 2002. p. 95-114.

JULIA, Dominique. A cultura escolar como objeto histórico. Revista Brasileira de História da Educação, São Paulo, n. 1, jan./ jun., 2001.

Disciplinas escolares: objetivos, ensino e apropriação. In: MACEDO, Elizabeth; LOPES, Alice Casimiro (Orgs.). Disciplinas e integração curricular: histórias e políticas. Rio de Janeiro: DP\&A, 2002. p. 37-71.

LAYTON, David. Science for the people: the origins of the school science curriculum in England. Londres: George Allen \& Unwin, 1973.

LE GOFF, Jacques. Documento/monumento. In: Memória-história. Porto: Enciclopédia Einaudi; Imprensa Nacional; Casa da Moeda, 1985

LOPES, Alice Casimiro. Currículo de ciências do Colégio de Aplicação da UFRJ (1969-1998): um estudo sócio-histórico. TEIAS, Rio de Janeiro, ano 1, n. 2, p. 31-94, jul./dez. 2000.

LORENZ, Karl M. As reformas do ensino das ciências no ensino secundário brasileiro nas décadas de 1960 e 1970. Revista Portuguesa de Pedagogia, Coimbra, ano 39, n. 1, 2004.

MACEDO, Elizabeth. Aspectos metodológicos em história do currículo. In: OLIVEIRA, Inês Barbosa de; ALVES, Nilda (Orgs.). Pesquisa no/do cotidiano das escolas sobre redes de saberes. Rio de Janeiro: DP\&A, 2002. p. 131-148.

NUNES, Clarice. Articulação teórico-empírica na pesquisa histórica: notas de estudo. In: INEP. Seminário História da Educação Brasileira: a ótica dos pesquisadores. Brasília: INEP, abr. 1995. p. 12-19. (Série Documental, Eventos, n. 6).

SELLES, Sandra Escovedo; FERREIRA, Marcia Serra. Influências histórico-culturais nas representações sobre as estações do ano em livros didáticos de ciências. Ciência \& Educação, Bauru, v. 10, n. 1, p. 101-110, 2004.

Disciplina escolar biologia: entre a retórica unificadora e as questões sociais. In: MARANDINO, Marta et al. (Orgs.). Ensino de biologia: conhecimentos e valores em disputa. Niterói: EDUFF, 2005. p. 50- 62. 
VENÂNCIO FILHO, Francisco. 0 conceito das Ciências físicas e naturais na escola secundária. In: Peixoto, Afrânio et al. Um grande problema nacional. Rio de Janeiro: Irmãos Pongetti, 1940. p. 87-129.

VIEIRA, Marcus V. A construção do conhecimento na ciência ecologia. In: ENCONTRO REGIONAL DE ENSINO DE BIOLOGIA, 2., 2003, Niterói. Anais... Niterói: SBEnBI0 (Regional 2: RJ/ES), 2003. p. 31-36.

Recebido em: 05.03.2012

Aprovado em: 31.10 .2012

Maria Margarida Gomes é doutora em Educação pela Universidade Federal Fluminense (UFF), professora da Faculdade de Educação da Universidade Federal do Rio de Janeiro (UFRJ), docente do Programa de Pós-Graduação em Educação dessa mesma universidade e pesquisadora do Núcleo de Pesquisas em Currículo (NEC) e do Projeto Fundão Biologia (UFRJ).

Sandra Escovedo Selles é doutora em Educação em Ciências pela University of East Anglia, Inglaterra, professora da Faculdade de Educação da Universidade Federal Fluminense (UFF), coordenadora do Programa de Pós-Graduação em Educação dessa mesma universidade e pesquisadora do Conselho Nacional de Desenvolvimento Científico e Tecnológico (CNPq). Coordena o grupo de pesquisa Currículo, Cultura \& Docência (http://www.wix.com/grupo_de_pesquisa/cdc\#!linhasde-pesquisa).

Alice Casimiro Lopes é doutora em Educação pela Universidade Federal do Rio de Janeiro (UFRJ), professora do Programa de Pós-Graduação em Educação dessa mesma universidade, pesquisadora do Conselho Nacional de Desenvolvimento Científico e Tecnológico (CNPq) e Cientista do Nosso Estado, da Fundação Carlos Chagas Filho de Amparo à Pesquisa do Estado do Rio de Janeiro (FAPERJ). Coordena o grupo de pesquisa Políticas de Currículo e Cultura (www.curriculo-uerj.pro.br). 